\title{
PEMERIKSAAN KESEHATAN, DETEKSI ANEMIA, DAN PENANGANANNYA PADA PESERTA POSYANDU LANSIA DI KECAMATAN GONDANGREJO KABUPATEN KARANGANYAR
}

\section{MEDICAL EXAMINATION, ANEMIA DETECTION AND TREATMENT ON ELDERLY HEALTH CENTER PARTICIPANTS IN GONDANGREJO KARANGANYAR DISTRICT}

Devi Usdiana Rosyidah, Zahra Hafizha Fitria Anam, Iqbal Maulana

Fakultas Kedokteran Universitas Muhammadiyah Surakarta

Korespondesi: Devi Usdiana Rosyidah. Alamat Email : dur203@ums.ac.id

\begin{abstract}
ABSTRAK
Data angka kejadian anemia pada lansia masih menjadi fenomena gunung es. Keadaan sosial ekonomi masyarakat gondangrejo sebagian besar menengah kebawah. Pemeriksaan kesehatan lansia di posyandu dikerjakan oleh tenaga non medis yang kemampuannya terbatas. Hasil survei menunjukkan kejadian anemia lansia ditemukan secara tidak sengaja saat pasien periksa ke dokter untuk keluhan penyakit lain. Keluarga menganggap kesehatan lansia bukan prioritas. Pengabdian masyarakat ini bertujuan untuk melakukan skrining kejadian anemia lansia dan memberikan solusi penanganan bagi peserta yang menderita anemia. Pemeriksaan kesehatan meliputi anamnesis, pemeriksaan fisik, pengecekan kadar $\mathrm{Hb}$, dan analisis kemungkinan penyebab anemianya. Jumlah responden 80 orang yang terdiri dari 30 orang laki-laki dan 50 orang perempuan, dengan angka kejadian anemia sebanyak 10 orang (12,50\%) berupa anemia ringan akibat penyakit yang telah diderita responden sebelumnya. Keberlanjutan dari temuan ini telah dilakukan edukasi, pemberian leaflet dan tata laksana sesuai kondisi masing-masing. Anemia pada lansia perlu dideteksi dini dengan metode jemput bola (skrining rutin). Metode ini memudahkan dalam pemberian tata laksana seawal mungkin, pencegahan morbiditas, dan mortalitas akibat anemia maupun penyakit primernya.
\end{abstract}

Kata kunci : Anemia, Lansia, Pemeriksaan Kesehatan, Solusi

ABSTRACT

Data on the incidence of anemia in the elderly was still an iceberg phenomenon. The socio-economic conditions of Gondangrejo's people are mostly lower-middle class. Health checks for the elderly at posyandu are carried out by non-medical personnel with limited abilities. The survey showed that the incidence of anemia in the elderly was found accidentally when a patient went to a doctor for complaints of other diseases. Families consider the health of the elderly was not a priority. The aims of this community service were screening the incidence of anemia in the elderly and providing solutions for participants who suffered from anemia. The medical examination included anamnesis, physical examination, haemoglobin level check, and the possible causes of anemia analysis. Total respondents were 80 consisting of 30 men and 50 women. The incidence of anemia was 10 people (12.30\%) with mild anemia because of their primary disease. The continuation of this case has been carried out by education, leaflet distribution, and management according to personal condition. Anemia in the elderly needs to be detected early with the ball pick method (routine screening). This action facilitated as soon treatment, prevention of morbidity or mortality due to anemia and primary diseases.

Keywords: Anemia, Elderly, Medical Examination, Solutions 


\section{PENDAHULUAN}

Anemia adalah salah satu masalah jiwa (Permenkes RI, 2016). Data jumlah kesehatan lansia, dengan penyebab tersering penduduk usia diatas 60 tahun di kecamatan kedua adalah anemia karena penyakit kronik Gondangrejo Karanganyar berjumlah 820 orang, (Octariando, 2014). Efek dari anemia pada lansia antara lain penurunan kinerja fisik, berkurangnya fungsi kognisi, dan risiko kematian yang meningkat (Wicaksono dan Noer, 2013). Anemia merupakan suatu gejala yang ditandai oleh penurunan kadar hemoglobin, jumlah eritrosit dan volume eritrosit persatuan milimeter darah. Anggapan yang tidak baik bila anemia pada lansia dianggap sebagai suatu kewajaran dan tidak dapat dihindari. Penanganan masalah ini seharusnya sudah dimulai sedini mungkin (Zahra dkk, 2019).

Kriteria lanjut usia ada beberapa perbedaan. Masa lansia awal dimulai sejak usia 45 - 59 tahun, lansia mulai usia 60 - 69 tahun dan masa lansia risiko tinggi ( $>70$ tahun atau usia $\geq$ 60 tahun dengan masalah kesehatan (Permenkes RI, 2016).

Jumlah penduduk lanjut usia (60+) diperkirakan akan meningkat pada tahun 2020 menjadi 27,1 juta jiwa, pada tahun 2025 menjadi 33,7 juta jiwa dan tahun 2035 sejumlah 48,2 juta dengan rincian 430 orang laki-laki, dan 390 orang perempuan (BPS Kab. Karanganyar, 2019).

Angka morbiditas dan multi morbiditas akibat peningkatan populasi lansia di Indonesia menimbulkan masalah kesehatan dimasyarakat (Anorital, 2015). Pada tahun 2019, jumlah penduduk lansia di Indonesia mencapai 7 persen dari total penduduk. Jumlah ini diperkirakan akan meningkat hingga 27 juta jiwa atau 9,9 persen. Berdasarkan studi oleh ketua Perhimpunan Geriatri Medik Indonesia (Pergami) tahun 2013, sebagian besar lansia tergolong kurang sehat karena renta. Hanya 13,2 persen yang masih sehat dan bisa beraktivitas normal. Lansia prefrail sebanyak 61,6 persen yaitu mereka memiliki penyakit tetapi masih dapat menjalani aktivitas dan sekitar 25 persen lansia frail (dalam kondisi sakit) serta tidak bisa melakukan aktivitas seperti biasa (Setiati, 2019).

Berdasarkan data Survei Sosial Ekonomi Nasional Tahun 2015, persentase rumah tangga yang memiliki lansia sebesar $24,1 \%$. Sementara 
lansia yang tinggal sendiri sebanyak 12,6\%, sisanya tinggal bersama anggota keluarga lainnya. Pada tataran implementasi, program Bina Keluarga Lansia (BKL) dan Lansia Tangguh belum berjalan dengan baik di semua wilayah (Cicih, 2019).

Angka harapan hidup di Indonesia semakin meningkat pada periode 2010-2015 sejumlah 70,1 tahun, pada periode tahun 20302035 menjadi 72,2 (Bappenas, BPS, dan UNFPA, 2013). Kondisi ini kurang sinkron dengan data Healthy Life Expectancy atau angka harapan hidup sehat hanya sebesar 62,1 tahun, artinya terdapat selisih sekitar delapan tahun berada dalam kondisi tidak atau kurang sehat. Mengingat selisihnya masih cukup tinggi, maka batasan umur seseorang dikatakan lansia di Indonesia apabila sudah mencapai usia 60 tahun.

Selain itu, dari karakteristik lainnya seperti ekonomi, masih banyak lanjut usia yang keburu tua sebelum kaya (Cicih, 2019).

Lansia merupakan kelompok usia yang rentan menderita penyakit atau gangguan kesehatan. Penyebutan lansia pada pengabdian masyarakat ini ditujukan pada manusia usia 55 tahun atau lebih. Lapisan masyarakat kelompok ini di Indonesia jumlahnya cenderung meningkat.
Anemia pada lansia kerap kali terjadi tanpa di sadari. Lansia bagian dari elemen masyarakat yang keberadaannya cenderung kurang mendapat perhatian. Anemia pada lansia paling sering terjadi secara kronik. Penyebabnya bisa karena penurunan fungsi pencernaan, asupan gizi yang kurang, maupun akibat penyakit lain yang diderita.

Perhatian terhadap kejadian anemia pada lansia sangat kurang dibanding kejadian anemia wanita usia subur atau remaja putri. Program pemberian tablet besipun sasarannya juga kepada wanita usia produktif. Data angka kejadian anemia pada lansia masih menjadi fenomena gunung es.

Keadaan sosial ekonomi masyarakat gondangrejo sebagian besar adalah menengah kebawah. Mata pencaharian penduduk kebanyakan adalah petani, buruh bangunan, buruh pabrik, penjual makanan keliling, dan pekerjaan borongan seperti membungkus sedotan, melipat dan mengelem amplop, serta sebagian besar lain hanya ibu rumah tangga biasa. Kondisi ini menyebabkan keluarga lebih fokus pada pemenuhan kebutuhan hidup seharihari dan mengabaikan monitoring kesehatan keluarga terutama lansia. 
Pemeriksaan kesehatan pada lansia di posyandu masih banyak dikerjakan oleh tenaga non medis yang kemampuannya terbatas. Perhatian dari keluargapun sering kali kurang, menganggap kesehatan mereka sudah sewajarnya menurun. Apalagi bila lansia tersebut sudah tidak produktif dan cenderung membebani ekonomi keluarga.

\section{TUJUAN DAN MANFAAT}

Tujuan pengabdian masyarakat ini adalah untuk mengetahui kesehatan fisik umum dan kejadian anemia lansia di Kecamatan Gondangrejo Kabupaten Karanganyar, serta memberikan solusi penanganan bagi peserta yang ditemukan menderita anemia.

\section{METODE PELAKSANAAN KEGIATAN}

Metode kegiatan pengabdian masyarakat yang dilakukan adalah kegiatan pemeriksaan kesehatan dan pengecekan kadar $\mathrm{Hb}$ (Hemoglobin) responden lansia. Setelah itu dilakukan analisis penegakan diagnosis anemia serta penyebabnya. Kemudian peserta diberikan tata laksana sesuai penyakit yang mendasari dan suplemen zat besi. Disamping itu responden dan keluarga diberikan edukasi langsung dan leaflet mengenai diet sehat lansia antianemia. Bila penyakit yang mendasari memerlukan pemeriksaan lanjutan dan pasien memiliki fasilitas jaminan kesehatan nasional (JKN), maka pasien diberikan rujukan ke rumah sakit.

\section{HASIL DAN DISKUSI}

Kegiatan pengabdian masyarakat ini telah dilaksanakan selama bulan Juni - Agustus 2020. Berkaitan dengan adanya pandemi Covid-19 yang dialami Indonesia termasuk di kecamatan Gondangrejo kabupaten Karanganyar sejak bulan maret 2020 sampai sekarang dan tidak dapat dipastikan kapan pandemi ini akan berakhir, mengakibatkan pelaksanaan kegiatan ini sedikit tertunda. Efek lain dari pandemi Covid-19 ini menyebabkan diberlakukannya pembatasan kegiatan yang mengumpulkan orang banyak termasuk kegiatan posyandu lansia. Oleh karenanya, maka pelaksanaan kegiatan PKM ini dialihkan dari yang semula di posyandu lansia ke Klinik Pratama Rawat Jalan Banyubiru yang beralamat di dusun Ngledok RT 5 RW 7 Kecamatan Gondangrejo Kabupaten Karanganyar. Responden kegiatan diambil dari pasien berusia lansia yang kebetulan hadir ke klinik untuk memeriksakan diri.

Teknis kegiatan dilaksanakan bersamaan saat pasien sedang diperiksa, meliputi anamnesis, pemeriksaan fisik umum, pengecekan kadar $\mathrm{Hb}$ 
dengan alat $H b$ stick dan edukasi personal kepada

pasien langsung serta keluarga yang mengantar.

Berhubung waktu pelaksanaan kegiatan berada di

masa pandemi Covid-19, maka pemeriksa menggunakan protokol kesehatan berupa masker bedah, baju pelindung, faceshield dan handscoen, sedangkan pasien dan keluarga cukup menggunakan masker.

Kecamatan Gondangrejo terdiri dari 13 desa, 78 dusun dan 166 dukuh. Desa-desa tersebut adalah: Jatikuwung, Selokaton, Wonorejo, Tuban, Plesungan, Bulurejo, Rejosari, Jeruksawit, Wonosari, Kragan, Karangturi, Krendowahono, dan Dayu. Dari seluruh responden berjumlah 83 orang, terdapat 3 orang yang tidak memenuhi syarat domisili di kecamatan Gondangrejo dan usia $<55$ tahun, sehingga total responden 80 orang yang memenuhi syarat domisili. Berikut sebaran jumlah responden di tiap desa (lihat tabel 1).

Tabel 1 Sebaran Responden di Tiap Desa di Kecamatan Gondangrejo

\begin{tabular}{|c|c|c|}
\hline No & Nama Desa & $\begin{array}{l}\text { Jumlah responden } \\
\text { (orang) }\end{array}$ \\
\hline 1 & Wonorejo & 14 \\
\hline 2 & Plesungan & 0 \\
\hline 3 & Jatikuwung & 28 \\
\hline 4 & Selokaton & 6 \\
\hline 5 & Bulurejo & 0 \\
\hline 6 & Rejosari & 1 \\
\hline 7 & Jeruksawit & 16 \\
\hline 8 & Karangturi & 1 \\
\hline 9 & Kragan & 5 \\
\hline 10 & Wonosari & 9 \\
\hline 11 & Dayu & 0 \\
\hline 12 & Tuban & 0 \\
\hline \multirow[t]{2}{*}{13} & Krendowahono & 0 \\
\hline & Total & 80 \\
\hline
\end{tabular}

Sumber : data primer, 2020

Secara umum karakteristik responden kelamin, usia, riwayat penyakit yang diderita, pengabdian masyarakat berdasarkan jenis dan kadar $\mathrm{Hb}$ dapat dilihat pada Tabel 2. 
Tabel 2 : Karakteristik Responden Di Tiap Desa Di Kecamatan Gondangrejo

\begin{tabular}{|c|c|c|c|}
\hline \multicolumn{2}{|c|}{ Karakteristik Responden } & $\begin{array}{l}\text { Jumlah } \\
\text { (orang) }\end{array}$ & $\%$ \\
\hline \multicolumn{4}{|c|}{ Jenis kelamin : } \\
\hline 1. & Laki-laki & 30 & 37,50 \\
\hline 2. & Perempuan & 50 & 62,50 \\
\hline \multicolumn{4}{|c|}{ Usia (tahun) : } \\
\hline 1. & $55-60$ & 12 & 15 \\
\hline 2. & $61-65$ & 23 & 28,75 \\
\hline 3. & $66-70$ & 7 & 8,75 \\
\hline 4. & $>70$ & 38 & 47,50 \\
\hline \multicolumn{4}{|c|}{ Riwayat penyakit yang diderita : } \\
\hline 1. & DM & 10 & 13 \\
\hline 2. & HT & 16 & 20 \\
\hline 3. & DM dengan HT & 8 & 10 \\
\hline 4. & Jantung (CHF, IHD) & 3 & 4 \\
\hline 5. & Pencernaan (Gastritis, GERD, hemoroid) & 19 & 24 \\
\hline 6. & Sendi, otot dan tulang (OA, GA, LBP, artritis, myalgia) & 13 & 16 \\
\hline 7. & Lain-lain & 11 & 14 \\
\hline \multicolumn{4}{|c|}{ Kadar $\mathrm{Hb}$} \\
\hline 1. & Anemia (laki-laki $<13 \mathrm{mg} / \mathrm{dL}$, perempuan $<12 \mathrm{mg} / \mathrm{dL}$ ) & 10 & 12,50 \\
\hline 2. & Tidak anemia & 70 & 87,50 \\
\hline
\end{tabular}

Sumber : data primer, 2020

Keterangan : DM (diabetes melitus), HT(hipertensi), CHF (cronic heart faillure), IHD (ischemic heart disease), GERD (gastroesofageal reflux disease), OA (osteoartritis), GA (gout artritis), LBP (Low Back Pain).

Setelah dilakukan analisis data kadar $\mathrm{Hb}$, ditemukan sebanyak 10 orang atau $12,50 \%$ masuk kategori anemia ringan dari total 80 orang responden. Berdasarkan hasil anamnesis, dan pemeriksaan fisik, dapat disimpulkan bahwa penyebab anemia lansia sebagian besar adalah anemia sekunder akibat penyakit lain yang diderita responden sebelumnya (Tabel 3).

Tindak lanjut dari temuan ini, untuk pasien dengan kadar $\mathrm{Hb}$ diatas $11 \mathrm{mg} / \mathrm{dL}$ diberikan edukasi dan leaflet daftar makanan yang dianjurkan dan daftar makanan yang sebaiknya dihindari, sehingga dapat memperbaiki kadar $\mathrm{Hb}$ nya. Sedangkan untuk responden dengan kadar $\mathrm{Hb}$ kurang dari $11 \mathrm{mg} / \mathrm{dL}$ selain diberikan edukasi dan leaflet, pasien juga diberikan tata laksana farmakologi berupa tablet tambah darah dan tata laksana penyakit primer atau dengan merujuknya ke Rumah Sakit rujukan bila penyakit pasien memerlukan perawatan tindak lanjut dan pasien memiliki fasilitas kartu JKN (Jaminan Kesehatan Nasional). Dari data kejadian anemia didapatkan 3 orang (30\%) dari 10 penderita anemia yang memerlukan tata 
laksana dan 1 orang $(10 \%)$ dirujuk ke rumah

sakit. Leaflet edukasi sebagian besar di tinggal di klinik tempat kegiatan pengabdian untuk di sebarkan ke pasien lain.

Tabel 3 Data Pasien Anemia, Kemungkinan Penyebab Anemia (Diagnosis), Kepemilikan Kartu Jaminan Kesehatan Nasional, Dan Folow Up (Keberlanjutan)

\begin{tabular}{|c|c|c|c|c|c|c|c|c|}
\hline No. & $\begin{array}{l}\text { No. } \\
\text { RM }\end{array}$ & $\begin{array}{c}\text { Usia } \\
\text { (tahun) }\end{array}$ & $\begin{array}{c}\text { Kadar } \\
\mathrm{Hb} \\
(\mathrm{mg} / \mathrm{dL})\end{array}$ & $\begin{array}{c}\text { Tekanan } \\
\text { darah } \\
(\mathrm{mmHg})\end{array}$ & JK & Diagnosis & JKN & Folow Up (keberlanjutan) \\
\hline 1 & 8726 & 57 & 11,2 & $140 / 90$ & $\mathrm{P}$ & HT & - & leaflet \\
\hline 2 & 2882 & 58,4 & 11,7 & $120 / 80$ & $\mathrm{P}$ & Gastritis & $\mathrm{v}$ & leaflet \\
\hline 3 & 1858 & 59,7 & 12,5 & $85 / 60$ & $\mathrm{~L}$ & PPOK & $\mathrm{v}$ & leaflet \\
\hline 4 & 6113 & 72,2 & 11,7 & $120 / 80$ & $\mathrm{~L}$ & Gastritis & $\mathrm{v}$ & leaflet \\
\hline 5 & 7657 & 73 & 10,5 & $125 / 70$ & $\mathrm{~L}$ & Gastritis kronik & - & leaflet + tata laksana \\
\hline 6 & 195 & 73,4 & 11,3 & $130 / 90$ & $\mathrm{P}$ & Gastritis & $\mathrm{v}$ & leaflet \\
\hline 7 & 8791 & 79 & 12,9 & $110 / 70$ & $\mathrm{~L}$ & $\mathrm{DM}$ & - & leaflet \\
\hline 8 & 7613 & 80 & 12,4 & $150 / 90$ & $\mathrm{~L}$ & HT & - & leaflet \\
\hline 9 & 6639 & 65 & 10,3 & $160 / 100$ & $\mathrm{P}$ & $\mathrm{CHF}$ & $\mathrm{v}$ & leaflet + tata laksana + rujuk \\
\hline 10 & 5946 & 62,1 & 10,6 & $130 / 80$ & $\mathrm{P}$ & Ischialgia & $\mathrm{v}$ & leaflet + tata laksana \\
\hline
\end{tabular}

Sumber : data primer, 2020

Keterangan : JK (jenis kelamin), PPOK (Penyakit Paru Obstruktif Kronik)

Hasil pengabdian kepada masyarakat ini menambah data kejadian anemia di kecamatan Gondangrejo. Kejadian anemia yang ditemukan dari responden masih dalam kategori ringan berdasar kadar $\mathrm{Hb}$, namun 3 orang perlu tata laksana medikamentosa dan 1 orang dirujuk ke rumah sakit karena komorbid penyakit yang mendasarinya. Kondisi umum responden semuanya relatif masih baik, sehingga keberlanjutan penanganan anemianya lebih mudah dan memiliki prognosis baik. Tindakan keberlanjutan kegiatan ini dapat mencegah lebih dini perburukan kondisi kesehatan responden dan meningkatkan kualitas kesehatan masyarakat secara umum.

\section{SIMPULAN DAN SARAN}

Kesimpulan yang dapat diambil dari kegiatan pengabdian kepada masyarakat ini adalah anemia pada lansia perlu di deteksi dini agar tidak berlanjut ke perburukan dengan pemberian tata laksana seawal mungkin, sehingga mencegah morbiditas, dan mortalitas akibat anemia maupun penyakit primernya

Saran untuk kegiatan serupa yaitu bekerja sama dengan puskesmas atau instansi penyandang dana swasta yang mau dan mampu mendukung kegiatan sehingga cakupan jumlah responden lebih banyak dan mencakup wilayah yang lebih luas. 


\section{UCAPAN TERIMAKASIH}

Ucapan terima kasih kami sampaikan kepada Asosiasi Pendidikan Kedokteran dan Kesehatan Muhammadiyah (APKKM) yang telah memberikan dana hibah pengabdian kepada masyarakat periode 2019/2020 sehingga kegiatan ini dapat terlaksana.

\section{DAFTAR PUSTAKA}

Anorital, 2015. Morbiditas Dan Multi Morbiditas Pada Kelompok Lanjut Usia Di Indonesia. Artikel Riset. Jurnal Biotek Medisiana Indonesia. 4(2):77-88.

Bappenas, UNFPA, dan BPS., 2013. Proyeksi Penduduk Indonesia 2010-2035, Hasil Sensus Penduduk 2010. Jakarta: Kementrian PPN/Badan Perencanaan Pembangunan Nasional (Bappenas), UNFPA (United Nations Population Funds (UNFPA) dan BPS (Biro Pusat Statistik)

BPS Kabupaten Karanganyar, 2019. Kecamatan Gondangrejo dalam angka. Karanganyar : Biro Pusat Statistik Kabupaten Karanganyar

Cicih, L. H. M., 2019. Info Demografi. Volume 1. https://www.bkkbn.go.id/po- content/uploads/info

demo_vol_1_2019_jadi.pdf

Octariando, S., 2014. Karakteristik Penderita Anemia Pada Lansia Di Bagian Penyakit Dalam Rumah Sakit Muhammadiyah Palembang Periode 1 Juni 2012 - 1 Juni 2013. Skripsi.

Permenkes RI, 2016. Peraturan Menteri Kesehatan Republik Indonesia Nomor 25 Tahun 2016 Tentang Rencana Aksi Nasional Kesehatan Lanjut Usia Tahun 20162019. http://hukor.kemkes.go.id/uploads/produk hukum/PMK No. $25 \mathrm{ttg}$ Rencana Aksi Nasional Kesehatan_Lanjut Usia_Tahu n 2016-2019.pdf

Setiati, S. 2019. Hanya 13,2 Persen Lansia di Indonesia yang Sehat. https://sains.kompas.com/read/2019/07/0 5/120500723/hanya-13-2-persen-lansiadi-indonesia-yang-sehat.

Wicaksono, T. and E. Noer, 2013. Perbedaan Asupan Zat Gizi Pada Lansia Anemia Dan Non Anemia, Journal of Nutrition College, 2(3) : 358-363.

Zahra, A.L., Putrawan, I.B., Dharmayuda, T.G. 2019. Karakteristik Anemia Pada Lansia Di RSUP Sanglah Denpasar Pada Bulan Januari-Juni 2017. Intisari Sains Medis 10(1): 155-158. 